\title{
The Role of Mass Media and Journalism in Risk Communication
}

\section{Tanja Perko*}

University of Antwerp and Belgian Nuclear Research Centre SCK•CEN, Belgium

An average individual in today's society is exposed to a large amount of risk related information, definitely larger than one can easily absorb. Risk has become an important element in our daily life as we live, according to Beck, in "a risk society". In risk societies risk related information is a prevalent type of information distributed or produced by mass media and is frequently a subject of journalism.

In a risk society, risk communication is one of the most important aspects of risk management. Risk communication in democratic societies is an interactive exchange of information and opinions concerning risks and risk management among the risk assessors, risk managers, consumers and other interested parties, usually referred to as stakeholders, by different means of mass communication. The right-to-know and participate principle is nowadays enshrined in local, national, regional and international, and trans-national laws and regulations. But the precise role of mass media and journalism in nowadays "risk society" still remains to be determined and should be an active subject of research by the communication scholars.

Namely, scholars of mass communication and journalism have the opportunity to draw upon theoretical and empirical strands to address not only the role of mass communication and journalism in general education and in the distribution of information related to risks, which are both highly investigated topics, but also in understanding and clarifying many of the central challenges of our rapidly changing world, influencing the role of mass media and journalism, a few of which we list below;

- One-way risk communication is increasingly replaced by multidirectional transmission.

- The new mass media play an important role in dissemination of risk related information. However, there are high stakes involved in struggles over ownerships of these media.

- The globalization of our living environment eliminates borders for the risk events and risk perceptions.

- Several social changes and challenges have recently brought about an increase in real or perceived societal and political risks and have influenced the use of mass media recently, such as the Arab Spring, the Fukushima nuclear accident and the global financial crisis.

- The credibility and trustworthiness of new sources of risk related information, as well censorship or overload of information in the new media are becoming more crucial.

- There is a tendency of the growing failure of risk managers and communicators to keep up with the technological changes in information systems used for risk communication.

On the other hand, it has been known for a long time that mass media are the most prominent information channel related to risk communication for the general public. They are used by different stakeholders and play the role of a "watchdog" of a society. However, they also have to fulfill the economic aspects of publishing or broadcasting, with "If it bleeds, it leads" being a well-known phenomenon in journalism. Moreover, mass media and journalism play a progressively more important role in contemporary crisis situations. They help create, shape and terminate a crisis.

Journalists do not only report about the reality, they also influence it. Communication scholars point out that journalists have an active role to play in reporting about an event (crisis). They represent, interpret, and construct it and the related political and public salience of various issues is partly driven by the media coverage. Research has shown that when media increase their attention to a given issue, the political elites jump on the bandwagon by stating their opinion, asking parliamentary questions, tabling law proposals, or issuing executive orders.

In view of the social and technological changes discussed earlier, the question now becomes whether these findings from a earlier period of mass media and journalism are still relevant today, or whether perhaps a redefinition of the role of mass media and journalism in risk communication is due.

If the latter is the case, we need to adopt the methodology of mass communication research to the newly raised situation and link it to research in other related areas. The topics studied by mass communication field related to risk can be extraordinarily diverse. They can range from extremely micro accounts of the use of twitter in natural disasters to extremely macro accounts of global flows of risk related information and influence. But the diversity of empirical objects of research can pose methodological problems. However, this should simply be viewed as another research opportunity in the development of scientific methods themselves. One promising research tool worth investigating in this regard may be the so called mixed methods, which combine qualitative and quantitative approaches.

In short, our goal should not be to praise existing efforts but rather to indicate challenges. In order to investigate the changes we are witnessing, research on mass communication has to seek stronger connections among its different sub-disciplines and to some extent, among different lines of investigation. Lack of integration and critical reflection is a problem related to both the ability of empirical research to have deep and cumulative scholarly significance, as well as the ability of the researchers to say why their work really matters. One of the possible remedies might be the emerging presence of an open access journals, whose important contributions to information availability can lead to more coherence in the field and raise research productivity levels and the level of engagement among researchers in shared intellectual and practical problems related to mass communication in today's risk society.

*Corresponding author: Tanja Perko, University of Antwerp and Belgian Nuclear Research Centre SCK•CEN, Belgium, Tel: +32479854832; E-mail: tperko@SCKCEN.BE

Received January 10, 2012; Accepted January 10, 2012; Published January 12 2012

Citation: Perko T(2012) The Role of Mass Media and Journalism in Risk Communication J Mass Communicat Journalism 2:e110. doi:10.4172/2165-7912.1000e110

Copyright: (c) 2012 Perko T. This is an open-access article distributed under the terms of the Creative Commons Attribution License, which permits unrestricted use, distribution, and reproduction in any medium, provided the original author and source are credited. 